\title{
The results pesticide residues research in crops from the areas of provinces Silesia and Opole in 2011-2012
}

\section{Wyniki badań pozostałości środków ochrony roślin w płodach rolnych z terenów województw śląskiego i opolskiego w latach 2011-2012}

\author{
Klaudia Pszczolińska, Urszula Rzeszutko, Izabela Domańska, Justyna Wlazło, Joanna Rolnik
}

\section{Summary}

In the years 2011-2012 in Laboratory of Pesticide Residue Research in Sośnicowice, 226 samples were examined under official control of testing pesticide residues in agricultural crops. The samples for testing were supplied by the Provincial Inspectors Plant Protection and Seed in Katowice and Opole. Within two years the laboratory received 139 vegetable samples (which is 61\% of the tested material), 63 fruit samples (27.9\%), 15 mushroom samples (6.6\%) and 9 samples of cereals (4\%). The analyses of samples detected 18 active substances authorized for use. Exceeding of the maximum residue levels was found in three active substances and three active substances of plant protection products prohibited for use in a given assortment were also found. In all cases, the information notice was sent under the RASFF (Rapid Alert System for Food and Feed).

Key words: pesticide residue, fruit, vegetables, arable crops, monitoring

\section{Streszczenie}

W latach 2011-2012, w Laboratorium Badania Pozostałości Środków Ochrony Roślin w Sośnicowicach przebadano 226 próbek w ramach urzędowej kontroli badania pozostałości środków ochrony roślin w płodach rolnych. Próbki do badań dostarczane były przez Inspektorów Wojewódzkich Inspekcji Ochrony Roślin i Nasiennictwa w Katowicach i Opolu. W przeciągu dwóch lat do laboratorium dostarczono 139 prób warzyw (co stanowi 61\% badanego materiału), 63 próby owoców (27,9\%), 15 prób grzybów (6,6\%) oraz 9 prób zbóż (4\%). W wyniku przeprowadzonych analiz w badanych próbkach wykryto 18 substancji czynnych dopuszczonych do stosowania. Przekroczenia najwyższych dopuszczalnych poziomów pozostałości stwierdzono w przypadku trzech substancji czynnych oraz wykryto trzy substancje czynne środków ochrony roślin niedozwolonych do stosowania w danym asortymencie. We wszystkich przypadkach wysłano powiadomienia informacyjne w ramach systemu RASFF (Rapid Alert System for Food and Feed).

Słowa kluczowe: pozostałości środków ochrony roślin, owoce, warzywa, płody rolne, monitoring

Instytut Ochrony Roślin - Państwowy Instytut Badawczy

Oddział Sośnicowice

Laboratorium Badania Pozostałości Środków Ochrony Roślin

Gliwicka 29, 44-153 Sośnicowice

k.pszczolinska@ior.gliwice.pl 


\section{Wstęp / Introduction}

Powszechnie stosowane środki ochrony roślin to liczna i zróżnicowana grupa związków chemicznych, która trafia do środowiska stanowiąc źródło potencjalnego zagrożenia dla zdrowia ludzkiego i środowiska. Niezbędne jest kontrolowanie pozostałości substancji czynnych (s.cz.) środków ochrony roślin w zróżnicowanym asortymencie roślinnym. Laboratorium Badania Pozostałości Środków Ochrony Roślin w Sośnicowicach wykonywało analizy pozostałości s.cz. środków, w ramach programu wieloletniego Instytutu Ochrony Roślin - Państwowego Instytutu Badawczego (IOR - PIB) „Ochrona roślin uprawnych z uwzględnieniem bezpieczeństwa żywności oraz ograniczenia strat w plonach i zagrożeń dla zdrowia ludzi, zwierząt domowych i środowiska", finansowanego przez Ministra Rolnictwa i Rozwoju Wsi.

Badania pozostałości środków ochrony roślin w płodach rolnych, jak też $\mathrm{w}$ glebie $\mathrm{i}$ wodach (źródła powierzchniowe $\mathrm{i}$ wody gruntowe), prowadzone są od wielu lat, a ich wyniki stanowią cenny materiał badawczy umożliwiający ocenę wpływu stosowanych środków chemicznych na środowisko i zdrowie ludzi (Sadowski i Kucharski 2003; Kucharski i Domaradzki 2009). Wieloletnie obserwacje pozwalają na analizę zmian, jakie zachodzą w praktyce stosowania chemicznych środków ochrony roślin oraz ocenę ich skutków.

Przedstawiono wyniki badań monitoringu pozostałości środków ochrony roślin w płodach rolnych pochodzących z terenu województwa opolskiego i śląskiego prowadzonego w latach 2011-2012.

\section{Materiały i metody / Materials and methods}

Próby do badań pobierali losowo Inspektorzy Wojewódzkich Inspekcji Ochrony Roślin i Nasiennictwa (WIORiN) w Katowicach i Opolu, bezpośrednio z produkcji rolniczej - szklarni, tuneli foliowych, gruntu, sadów, a także $\mathrm{z}$ pomieszczeń magazynowych. W latach 2011-2012 do laboratorium dostarczono 139 prób warzyw (co stanowi $61 \%$ badanego materiału), 63 próby owoców (27,9\%), 15 prób grzybów $(6,6 \%)$ oraz 9 prób zbóż (4\%).

Program kontroli obejmował w roku 2011 - 147 substancji czynnych, zaś w roku 2012 o 16 substancji więcej. Do oznaczeń pozostałości s.cz. stosowano metody wielopozostałościowe umożliwiające wykrycie wielu związków w jednym toku analitycznym, zgodnie z obowiązującymi normami (SANCO 2009, 2011). Poprawność metod sprawdzono poprzez udział $\mathrm{W}$ międzylaboratoryjnych badaniach biegłości organizowanych przez The Food Analysis Performance Assessment Schame (FAPAS) oraz Unię Europejską (European Comission's Proficience Test on Pesticide Residues in Fruit and Vegetables). Laboratorium uzyskało w nich zadawalające oceny, potwierdzając tym samym poprawność uzyskiwanych wyników.

Do jakościowego i ilościowego oznaczenia pozostałości środków ochrony roślin zastosowano technikę rozpraszania matrycy na fazie stałej MSPD (matrix solid phase dispersion) (Kadeneczki i wsp. 1992). W zależności od asortymentu część próbek była poddana dodatkowo oczyszczeniu na kolumienkach SPE (Solid-Phase Extraction), wypełnionych żelem krzemionkowym. Oznaczenia w końcowym ekstrakcie wykonano na chromatografie gazowym Agilent 7890A, wyposażonym w detektory selektywne $\mu \mathrm{EC}$ (wychwytu elektronów) i NPD (azotowofosforowy) oraz kolumnę 5 MS UI. Jakościowe potwierdzenie uzyskanych wyników wykonano na chromatografie gazowym Agilent 7890A wyposażonym w detektor masowy. Pozostałości ditiokarbaminainów, wyrażone jako $\mathrm{CS}_{2}$ oznaczono spektrofotometrycznie (Chmiel 1979).

Uzyskane wyniki badań porównano $\mathrm{z}$ najwyższymi dopuszczalnymi poziomami pozostałości (NDP) obowiązującymi w Polsce i Unii Europejskiej (Rozporządzenie WE 2005). Przypadki przekroczeń NDP oraz stosowania niezalecanych środków ochrony roślin $\mathrm{w}$ danej uprawie (Ustawa 2003) były niezwłocznie zgłaszane w ramach systemu Rapid Alert System for Food and Feed (RASFF) (Ustawa 2006).

\section{Wyniki i dyskusja / Results and discussion}

Spośród 226 analizowanych próbek w 36 (15,9\%) stwierdzono obecność 61 pozostałości s.cz. środków ochrony roślin. Najwięcej pozostałości s.cz. zostało wykrytych w truskawkach (16 prób) w grupie owoców, a w przypadku warzyw najwięcej pozostałości stwierdzono W marchwi (5). W badanych próbach wykryto łącznie 18 różnorodnych związków chemicznych, w tym: $10 \mathrm{z}$ grupy fungicydów (ditiokarbaminiany, cyprodynil, fludioksonil, trifloksystrobina, boskalid, pirymetanil, propikonazol, chlorotalonil, iprodion, azoksystrobina), 5 z grupy insektycydów (diazynon, indoksakarb, chlorpiryfos, pirydaben, fenazachina) oraz 3 herbicydy (linuron, chlorprofam, lenacyl). Wśród zidentyfikowanych pozostałości najczęściej wykrywano boskalid (s.cz. fungicydów) - 13 prób (tab. 1).

Największy odsetek pozostałości stwierdzono w próbkach owoców (9,3\%), co w porównaniu z monitoringiem krajowym z lat 2010-2011 (Nowacka i wsp. 2011, 2012), potwierdza tendencję do występowania największej ilości pozostałości s.cz. W próbkach owoców. Odpowiednio w 2010 roku stwierdzono 41,7\% prób z pozostałościami, a w 2011 roku 58,7\%, pomimo tego, że ilość badanych prób owoców nie stanowi największego badanego asortymentu. Dane literaturowe i uzyskane wyniki potwierdzają, że owoce są grupą upraw, w której producenci najczęściej stosują chemiczne środki ochrony roślin.

W badanych próbkach stwierdzono obecność pozostałości wielokrotnych. Więcej niż jedną pozostałość odnotowano w 14 próbach. Najwyższy odsetek stanowiły próbki, w których obecne były dwie substancje czynne (50\%) (rys. 1). Najczęściej pojawiającym się zestawieniem s.cz. (5 prób) były fungicydy: cyprodynil i fludioksonil.

W trakcie analizy materiału roślinnego została potwierdzona obecność s.cz. środków ochrony roślin niezalecanych do ochrony uprawy marchwi: propikonazol (fungicyd), diazynon (insektycyd) - rok 2011 oraz uprawy selera: chlorpiryfos (insektycyd) - rok 2012. 
Tabela 1. Występowanie pozostałości s.cz. środków ochrony roślin w płodach rolnych

Table 1. Residues of active substances detected in crops

\begin{tabular}{|c|c|c|c|c|c|c|c|}
\hline \multirow{3}{*}{$\begin{array}{l}\text { Klasyfikacja } \\
\text { Classification }\end{array}$} & \multirow{3}{*}{$\begin{array}{l}\text { Produkt } \\
\text { Product }\end{array}$} & \multicolumn{2}{|c|}{$\begin{array}{c}\text { Liczba próbek } \\
\text { Number of samples }\end{array}$} & \multicolumn{3}{|c|}{$\begin{array}{l}\text { Próbki z pozostałościami } \\
\text { Samples with residues }\end{array}$} & \multirow{3}{*}{$\begin{array}{l}\text { Wartość lub zakres wykrytych } \\
\text { pozostałości } \\
\text { Value or range of found residues } \\
{[\mathrm{mg} / \mathrm{kg}]}\end{array}$} \\
\hline & & \multirow[t]{2}{*}{2011} & \multirow[t]{2}{*}{2012} & \multirow{2}{*}{$\begin{array}{l}\text { substancja czynna } \\
\text { active substance }\end{array}$} & \multicolumn{2}{|c|}{$\begin{array}{c}\text { liczba próbek } \\
\text { number of samples }\end{array}$} & \\
\hline & & & & & 2011 & 2012 & \\
\hline \multirow{5}{*}{$\begin{array}{l}\text { Owoce } \\
\text { Fruits }\end{array}$} & $\begin{array}{l}\text { borówka } \\
\text { blueberry }\end{array}$ & - & 2 & $\begin{array}{l}\text { dithiocarbamates } \\
\text { cyprodinil } \\
\text { fludioxonil }\end{array}$ & $\begin{array}{l}- \\
- \\
-\end{array}$ & $\begin{array}{l}1 \\
1 \\
1\end{array}$ & $\begin{array}{c}0,23 \\
0,09 \\
0,1\end{array}$ \\
\hline & $\begin{array}{l}\text { jabłko } \\
\text { apple }\end{array}$ & 2 & 9 & $\begin{array}{l}\text { indoxacarb } \\
\text { trifloxystrobin }\end{array}$ & $\begin{array}{l}- \\
-\end{array}$ & $\begin{array}{l}2 \\
1\end{array}$ & $\begin{array}{c}0,02-0,03 \\
0,04\end{array}$ \\
\hline & $\begin{array}{l}\text { malina } \\
\text { rasberry }\end{array}$ & 1 & 4 & $\begin{array}{l}\text { boscalid } \\
\text { cyprodinil } \\
\text { fludioxonil } \\
\text { pyrimethanil }\end{array}$ & $\begin{array}{l}1 \\
1 \\
1 \\
1\end{array}$ & $\begin{array}{l}- \\
- \\
- \\
-\end{array}$ & $\begin{array}{l}1,05 \\
1,02 \\
0,49 \\
0,33\end{array}$ \\
\hline & $\begin{array}{l}\text { porzeczka } \\
\text { currant }\end{array}$ & - & 6 & dithiocarbamates & - & 1 & 2,2 \\
\hline & $\begin{array}{l}\text { truskawka } \\
\text { strawberry }\end{array}$ & - & 29 & $\begin{array}{c}\text { dithiocarbamates } \\
\text { trifloxystrobin } \\
\text { boscalid } \\
\text { lenacil } \\
\text { fludioxonil } \\
\text { cyprodinil } \\
\text { pyridaben } \\
\text { fenazaquin }\end{array}$ & $\begin{array}{l}- \\
- \\
- \\
- \\
- \\
- \\
- \\
-\end{array}$ & $\begin{array}{c}7 \\
2 \\
12 \\
1 \\
4 \\
4 \\
1 \\
1\end{array}$ & $\begin{array}{c}0,05-0,75 \\
0,13 \\
0,02-1,1 \\
0,08 \\
0,03-0,11 \\
0,05-0,21 \\
0,14 \\
0,13\end{array}$ \\
\hline \multirow{6}{*}{$\begin{array}{l}\text { Warzywa } \\
\text { Vegetables }\end{array}$} & $\begin{array}{l}\text { marchew } \\
\text { carrot }\end{array}$ & 7 & 3 & $\begin{array}{l}\text { chlorpyrifos } \\
\text { diazinon } \\
\text { propiconazole }\end{array}$ & $\begin{array}{l}3 \\
1 \\
1\end{array}$ & $\begin{array}{l}2 \\
- \\
-\end{array}$ & $\begin{array}{l}0,02-0,41 \\
0,03 \\
0,07\end{array}$ \\
\hline & $\begin{array}{l}\text { pomidor } \\
\text { tomato }\end{array}$ & 2 & 18 & $\begin{array}{l}\text { chlorothalonil } \\
\text { iprodione } \\
\text { dithiocarbamates }\end{array}$ & $\begin{array}{l}- \\
- \\
-\end{array}$ & $\begin{array}{l}3 \\
1 \\
1\end{array}$ & $\begin{array}{c}0,21-0,65 \\
0,33 \\
0,1\end{array}$ \\
\hline & $\begin{array}{l}\text { ziemniak } \\
\text { potato }\end{array}$ & 14 & 10 & chloroprofam & 1 & - & 0,32 \\
\hline & pietruszka & & & linuron & 1 & - & 0,08 \\
\hline & $\begin{array}{l}\text { korzeń } \\
\text { parsley root }\end{array}$ & 4 & 12 & $\begin{array}{l}\text { chlorpyrifos } \\
\text { azoxystrobin }\end{array}$ & $\begin{array}{l}- \\
-\end{array}$ & $\begin{array}{l}1 \\
1\end{array}$ & $\begin{array}{c}0,015 \\
0,05\end{array}$ \\
\hline & $\begin{array}{l}\text { seler } \\
\text { celery }\end{array}$ & 1 & 1 & $\begin{array}{l}\text { azoxystrobin } \\
\text { chlorpiryfos }\end{array}$ & - & $\begin{array}{l}1 \\
1\end{array}$ & $\begin{array}{l}0,08 \\
0,07\end{array}$ \\
\hline
\end{tabular}

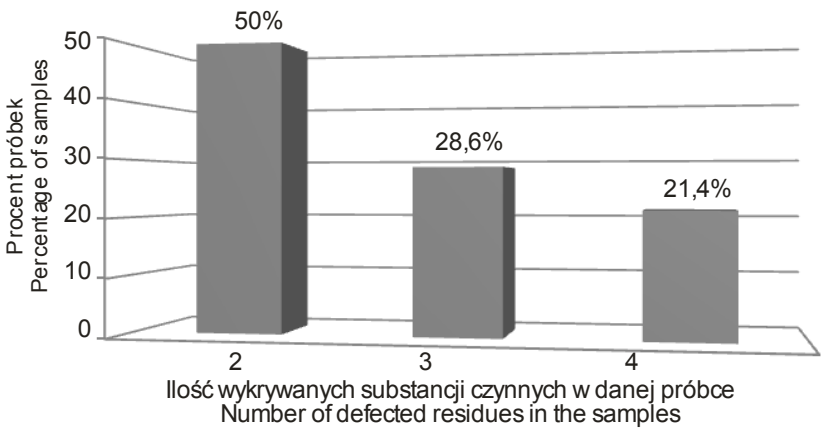

Rys. 1. Próbki z wielokrotnymi pozostałościami

Fig. 1. Samples with pesticide multiresidue

W 2011 oraz 2012 roku w próbkach marchwi wykryto przekroczenia NDP dla takich s.cz., jak: chlorpiryfos i diazynon (tab. 2). Otrzymane wyniki odniesiono do monitoringu krajowego w celu porównania wykrytych Tabela 2. Płody rolne, w których stwierdzono przekroczenia NDP przekroczeń. Według danych przedstawionych przez Nowacką (2012) w roku 2011 odnotowano dwa przekroczenia dla substancji diazynon w uprawie marchwi.

W przedstawionych przypadkach przekroczeń NDP oraz zastosowania niewłaściwego środka ochrony roślin dla danej uprawy niezwłocznie sporządzono powiadomienie w ramach systemu RASFF i przekazano do Wojewódzkich Inspekcji Ochrony Roślin i Nasiennictwa.

Próbek wolnych od wykrywalnych pozostałości, powyżej granic oznaczalności stosowanych metod analitycznych, było 84\%. Pozostałości nie stwierdzono w takich produktach, jak: czereśnia ( 2 - liczba badanych próbek), winogrona (2), gruszka (2), wiśnia (3), śliwka (1), kapusta (6), papryka (3), burak cukrowy (9) oraz ćwikłowy (16), fasola szparagowa (1), kapusta pekińska (1), kalafior (1), ogórek (17), sałata (4), bób (1), por (4), szczaw (1), cebula (3), pieczarki (15), pszenica (3), kukurydza (5), owies (1). 
Table 2. Crops with residues exceeding MRLs

\begin{tabular}{l|c|c|c|c|c}
\hline \multicolumn{1}{c|}{$\begin{array}{c}\text { Produkt } \\
\text { Product }\end{array}$} & $\begin{array}{c}\text { Rok } \\
\text { Year }\end{array}$ & $\begin{array}{c}\text { Substancja czynna } \\
\text { Active substance }\end{array}$ & $\begin{array}{c}\text { Liczba próbek z pozostałościami } \\
\text { powyżej NDP } \\
\text { Number samples with residues } \\
\text { above MRLs }\end{array}$ & $\begin{array}{c}\text { NDP } \\
\text { MRLs }\end{array}$ & $\begin{array}{c}\text { Wykryte przekroczenia } \\
\text { Detected violations } \\
{[\mathrm{mg} / \mathrm{kg}]}\end{array}$ \\
\hline $\begin{array}{l}\text { Marchew } \\
\text { Carrot }\end{array}$ & 2011 & chlorpyrifos & 1 & 0,10 & 0,30 \\
\hline $\begin{array}{l}\text { Marchew } \\
\text { Carrot }\end{array}$ & 2011 & diazinon & 1 & 0,01 & 0,03 \\
\hline $\begin{array}{l}\text { Marchew } \\
\text { Carrot }\end{array}$ & 2012 & chlorpyrifos & 1 & 0,10 & 0,41 \\
\hline
\end{tabular}

\section{Wnioski / Conclusions}

1. Na podstawie analizy 226 próbek płodów rolnych z terenu województwa opolskiego i śląskiego największy udział próbek $\mathrm{z}$ oznaczonymi pozostałościami stwierdzono w owocach $(9,3 \%)$.
2. W $84 \%$ analizowanych próbek nie stwierdzono wykrywalnych pozostałości s.cz. badanych środków ochrony roślin.

3. Najczęściej wykrywaną s.cz. był boskalid należący do grupy fungicydów.

4. Przeprowadzone badania wykazały przekroczenia NDP dla chlorpiryfosu i diazynonu w próbach marchwi (1,33\% wszystkich badanych prób).

\section{Literatura / References}

Chmiel Z. 1979. Spektrofotometryczne oznaczanie śladowych pozostałości dwuditiokarbaminianów w materiale roślinnym. Chem. Anal. 24: 505-511.

Kadeneczki L., Arpad Z., Gardi I., Ambrus A., Gyorfi L., Reese G., Ebing W. 1992. Column extraction of residues of severa; pesticides from fruits and vegetables: A simple multiresidue analysis method. J. AOAC Int. 75: 53-61.

Kucharski M., Domaradzki K. 2009. Pozostałości herbicydów w wybranych roślinach uprawnych - badania z lat 2000-2008. Fragm. Agron. 26 (4): 74-80.

Method Validation and quality control procedures for pesticide residues analysis in food end feed. Document $\mathrm{N}^{\circ}$ SANCO/10684/2009.

Method Validation and quality control procedures for pesticide residues analysis in food end feed. Document $\mathrm{N}^{0}$ SANCO/12495/2011.

Nowacka A., Gnusowski B., Walorczyk S., Drożdżyński S., Raczkowski M., Hołodyńska A., Frąckowiak D., Wójcik A., Ziółkowski A., Rzeszutko U., Domańska I., Jurys J., Łozowicka B., Kaczyński P., Rutkowska E., Jankowska M., Hrynko I., Szpyrka E., Rupar J., Rogozińska K., Kurdziel A., Słowik-Borowiec M., Michel M., Kuźmenko A., Szala J. 2011. Pozostałości środków ochrony roślin w płodach rolnych (rok 2010). [Pesticiode residues in Polish crops (2010)]. Prog. Plant Prot./Post. Ochr. Roślin 51 (4): $1723-1738$.

Nowacka A., Gnusowski B., Walorczyk S., Drożdżyński S., Raczkowski M., Hołodyńska A., Frąckowiak D., Wójcik A., Ziółkowski A., Przewoźniak M., Swoboda W., Rzeszutko U., Domańska I., Jurys J., Łozowicka B., Kaczyński P., Rutkowska E., Jankowska M., Hrynko I., Szpyrka E., Rupar J., Rogozińska K., Kurdziel A., Słowik-Borowiec M., Szala J., Szponik M., Michel M. 2012. Pozostałości środków ochrony roślin w płodach rolnych (rok 2011). [Pesticiode residues in Polish crops (2011)]. Prog. Plant Prot./Post. Ochr. Roślin 52 (4): 1106-1116.

Rozporządzenie WE 2005. Rozporządzenie (WE) nr 396/2005 Parlamentu Europejskiego i Rady Europy z dnia 23 lutego 2005 roku $\mathrm{z}$ późn. $\mathrm{zm}$. w sprawie najwyższych dopuszczalnych poziomów pozostałości pestycydów w żywności i paszy pochodzenia roślinnego i zwierzęcego oraz na ich powierzchni, zmieniające dyrektywę Rady 91/414/EWG (Dz. U. L 70, str. 1 z 16.03.2005., z późn. zm.).

Sadowski J., Kucharski M. 2003. Monitoring of herbicidal pollution in ground and surface water on arable land of South-West Poland. J. Plant Prot. Res. 43 (3): 241-245.

Ustawa z dnia 18 grudnia 2003 r. o ochronie roślin. 2004. Dz. U. Nr 11, poz. 94, z późn. zm.

Ustawa z dnia 25 sierpnia 2006 r. o bezpieczeństwie żywności i żywienia. Dz. U. Nr 171, poz. 1225, z późn. zm. 